\title{
Perspectives of In-situ/operando resonant inelastic X-ray scattering in catalytic energy materials science
}
Yi-Sheng Liu ${ }^{1}$, Per-Anders Glans ${ }^{1}$, Cheng-Hao Chuang ${ }^{1,2}$, Mukes Kapilashrami ${ }^{1,3}$, and Jinghua $\mathrm{Guo}^{1,4, \dagger}$

${ }^{1}$ Advanced Light Source, Lawrence Berkeley National Laboratory, Berkeley, California 94720

${ }^{2}$ Department of Physics, Tamkang University, Tamsui, Taiwan 250, R.O.C

${ }^{3}$ Center for Engineering Concepts Development, Department of Mechanical Engineering, University of Maryland, College Park, MD 20742

${ }^{4}$ Department of Chemistry and Biochemistry, University of California, Santa Cruz, California 95064

\begin{abstract}
Growing environmental concerns have renewed the interest for light induced catalytic reactions to synthesize cleaner chemical fuels from syngas. This, however, requires a sound understanding for the dynamics taking place at molecular level as a result of light-matter interaction. We present herein the principles of soft X-ray resonant emission spectroscopy (RXES) and resonant inelastic scattering (RIXS) and the importance of these spectroscopic techniques in materials science in light of their unique ability to emanate characteristic fingerprints on the geometric structure, chemical bonding charge and spin states in addition to chemical sensitivity. The addition of in-situ/operando capability offers new opportunities to project important material properties and functionalities under conditions nearly identical to the operational modes.
\end{abstract}

PACS numbers:

† Correspondence to: jguo@ lbl.gov 


\section{INTRODUCTION}

The ability of solar power to meet our increasing energy demands is today beyond doubt. For instance, solar energy can be converted to electricity and chemical fuels for energy use and storage if efficient and inexpensive energy conversion systems utilizing readily available earthabundant materials can be devised [1-4]. However, the solar energy conversion, and energy storage for practical applications requires materials that simultaneously fulfill several important requirements that relate to their electronic structure and chemical properties in order to ensure stability and efficient utilization of the solar spectrum [5]. Thus, a comprehensive understanding for a system's (e.g. photoelectric material complexes) principle properties and charge dynamics taking place at molecular level therein is crucial. Further, one must ask how do we learn about the electronic and atomic characteristics of novel materials for efficient solar energy conversion (photovoltaics), energy storage (Li-ion, and multivalent-ion batteries), and efficient catalytic activity and selectivity in catalysis (photocatalysis)? These are profound challenges that have been with us for decades but are presently more important than ever before. Clearly, in order to address these questions requires experimental capabilities that allow one to obtain fingerprints on the local electronic structure and charge symmetry that offers both high precision, and element selectivity.

Among the emerging experimental techniques, synchrotron based X-ray spectroscopy has been proven as a powerful tool in varying topics across the physical, chemical and biological researches in light of key experimental capabilities. X-rays originate from electronic transitions between a localized core state and a valence states, and is commonly divided into two energy regions: soft X-ray (100 eV to $2.0 \mathrm{keV})$ and hard X-ray (> $2.0 \mathrm{keV})$. Soft X-ray spectroscopy in particular provides important information about the electronic structure in elements with low effective atomic number (e.g. B, C, N, O) and transition metal (TM) elements by probing their K-edge, and L-edge respectively. . These are all elements that have left pronounced footprints in applications related to solar energy conversion, and energy storage.

Complementary to many "lab-based" X-ray spectroscopy techniques e.g. UV-vis spectroscopy, X-ray photoelectron spectroscopy (XPS) and Raman spectroscopy, synchrotron-based X-ray spectroscopy offers element selectivity owing to excitation of a core electron into the unoccupied 
density of states, or de-excitation from a valence electron into the core level. It details the local charge transitions, electronic structure, charge symmetry due to the dipole nature of the transitions, and local chemical environment in complex materials systems at high precision [6].

The two essential and widely employed synchrotron techniques in the soft X-ray range include (i) X-ray absorption spectroscopy (XAS), and (ii) X-ray emission spectroscopy (XES). While XAS probes the unoccupied density of states (conduction band), XES probes the occupied density of states (valence band) and thus the combination of the two projects the band gap by measuring the energy separation between the conduction band minimum (CBM) and valence band maximum (VBM) $[5,7,8]$.

The development of third generation synchrotron radiation light source has led to extremely bright undulator X-ray which makes photon demanding experimental technique, such as Resonantly Inelastic X-ray Scattering (RIXS), possible. Since RIXS is a second order optical process, it yields a lower signal (compare to XAS/and XPS, which is a first order process $[9,10]$ ), as monochromatized soft X-ray photons offer higher degree of energy selectivity that increases the chemical sensitivity of RIXS. In addition, synchrotron radiation offers the possibility for polarization dependent excitation that in turn distinguishes the anisotropic effect in RIXS spectra [11-13].

Given the continuous progress in the field renewable energy, and advances in synchrotron spectroscopy technique, we present herein a few examples to illustrate the current progress in the development of this experimental technique and its importance/contribution to the field of energy materials research, and possibly the in-situ/operando characterization of energy applications.

This review is comprised of five main sections: section 1 and 2 present the reader both a motivation for the importance of the X-ray spectroscopy techniques in the soft X-ray energy range, and their principles. Section 3 describes the experiments. Section 4 and 5 presents the latest developments that enable in-situ/operando of novel material complexes for energy applications, and a few key perspectives of in-situ studies in energy science (respectively).

\section{SOFT X-RAY SPECTROSCOPY}


Soft X-ray absorption spectroscopy (XAS), or soft X-ray absorption fine structure (NEXAFS) technique, has become a powerful tool to study surface molecules in solids $[14,15]$. When studying energy materials and devices it is necessary to perform the experiments in their real environment, i.e. liquid electrolytes in $\mathrm{Li}$-ion and $\mathrm{Mg}$-ion batteries $[16,17]$ or photocatalysts and electrochemical interface with liquid water[18, 19]. Here we will show how resonant soft X-ray emission spectroscopy (RXES) and resonant inelastic soft X-ray scattering (RIXS) can be used for in-situ/operando studies of wet systems such as batteries and photocatalysis.

\subsection{X-ray Absorption Spectroscopy}

The X-ray absorption spectrum of a given element is comprised of a set of edges, each corresponding to excitation of a different core electron. Electron levels with the quantum number $n$ equal to 1-4 are labeled K, L, M, and N levels, respectively. In the soft X-ray region, for light

elements (e.g. B, C, N, O, F, and $\mathrm{Na}$ ), the core vacancy left by the excited 1s electron is populated by a valence-orbital electron, and gives direct information about the chemical bonding. For the $3 \mathrm{~d}$ transition metal elements (e.g. Ti, V, Cr, Mn, Fe, Co, Ni, Cu), the core vacancy left by an excited $2 \mathrm{p}$ electron is populated by a valence-orbital electron, which sheds light about the $3 \mathrm{~d}$ electron behavior and $3 \mathrm{~d}$ orbital occupancies. 


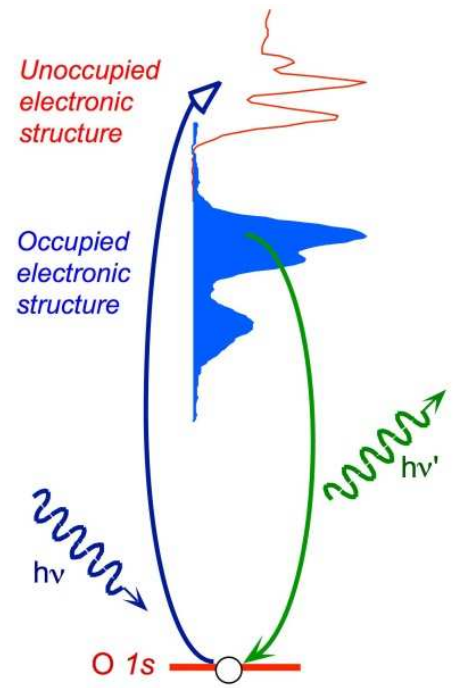

Fig. 1. The energy diagram to illustrate the X-ray absorption and emission processes.

The energy diagram presented in Fig. 1 illustrates the typical XAS transition process wherein a core level electron (for instance, $\mathrm{O} 1 \mathrm{~s}$ ) is excited into the unoccupied electronic states. The XAS spectra are recorded either in the total electron yield (TEY) detection mode [20], or in the total fluorescence yield (TFY) detection mode [21]. While the TEY-detection mode is surface sensitive (typically up to 5-10 nm below surface), TFY-detection mode reflects the "bulk" properties (ca. up to 100-200 nm below surface) and relies on the emitted X-ray photons (fluorescence) as core-levels are re-populated from the electrons of valence states. Both TEY-, and TFY-detection modes are based on secondary X-ray excitation and de-excitation processes. TEY detection is typically measured by using the sample drain current, which is limited to the non-insulating materials, and TFY detection may be distorted from a saturation effect resulting from the self-absorption effect [22, 23].

\subsection{Resonant Soft X-ray Emission Spectroscopy}

X-ray emission spectroscopy probes the occupied electronic states (valence band) by monitoring the emission (as core holes are populated by electrons from the valence orbitals) probability as a 
function of photons out. One major improvement in the performance of synchrotron radiation based soft X-ray emission spectroscopy is the high brightness of the third generation light source. Intense and tunable monochromatized X-ray beam enables resonantly excited soft X-ray emission spectroscopy.

The ability to tune the excitation energy of the synchrotron radiation, which thus selects the final energy state of the excited core electrons (a.k.a. resonant excitation), creates an additional degree of freedom in comparison with traditional way of excitations (for example, high-energy electron beam or characteristic X-ray excitations). [24-26]. One can mention a few examples, such as the site selectivity in high- $T_{\mathrm{c}}$ superconducting (HTSC) materials [26-28], femtosecond dynamics in molecules [29-31] by detuning from resonance, etc.

To demonstrate the sensitivity of this technique, Fig. 2 presents the variation in the emission spectra of $\mathrm{La}_{1.93} \mathrm{Sr}_{0.07} \mathrm{CuO}_{4}$ as a function of increasing excitation energy. The top panel of Fig. 2 reflects the typical O K-edge XAS spectrum of the high $\mathrm{T}_{\mathrm{C}}$ cuprate compound, wherein a distinct absorption edge at ca. $532 \mathrm{eV}$ is evident. The pre-edge XAS features have been assigned to the doping-induced hole states at $528.5 \mathrm{eV}$ and upper Hubbard band at $530.4 \mathrm{eV}$. Upon recording RXES spectra at different incident (excitation) photon energies alters the spectral profile (in the bottom panel of Fig. 2). In particular, the two RXES spectra excited at $528.5 \mathrm{eV}$ and $532.8 \mathrm{eV}$ exhibiting largely different spectral profile and are in accordance with the predictions of bandstructure calculations $[26,32]$ for the inequivalent oxygen sites $\mathrm{O}(1)$ and $\mathrm{O}(2)$ and thus provide the evidence of the $1 \mathrm{~s}$ core hole creation mainly at one or another type of $\mathrm{O}$ sites depending on the excitation energies. Also RXES spectra have been utilized to address the questions such as, impurity induced magnetism in carbon doped $\operatorname{In}_{2} \mathrm{O}_{3}$ [33] and molecular structure of liquid water [34] and other liquid systems [35, 36]. 


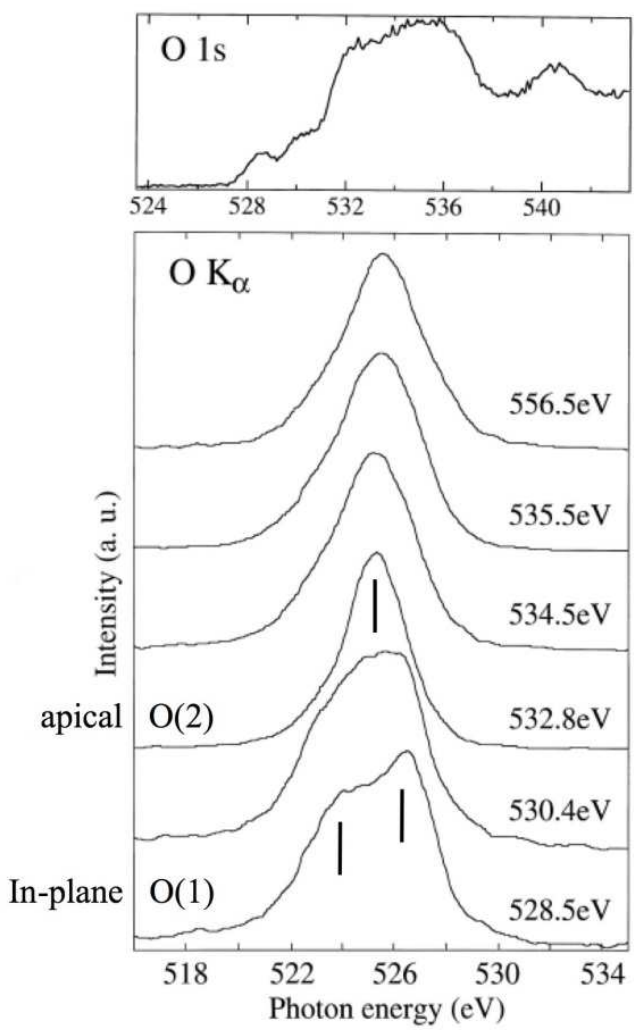

Fig. 2. O K-edge RXES spectra of $\mathrm{La}_{1.93} \mathrm{Sr}_{0.07} \mathrm{CuO}_{4}$ recorded at the various different excitation energies, and $\mathrm{O}$ 1sabsorption spectrum is shown on top. [Ref. 26]

\subsection{Resonant Inelastic Soft X-ray Scattering}

The introduction of energy selectively has also opened the new fields of study by disclosing many new features of soft X-ray resonant inelastic scattering (RIXS). The power of inelastic Xray scattering stems from their unique and direct way to measure the momentum resolved charge-charge correlation function in addition to the electronic structure. Final states probed via the channel of RIXS are related to the eigenvalues of the ground state Hamiltonian. Here the core-hole lifetime does not limit the spectral resolution, instead it has been proved that the corehole lifetime can be overcome by developing the high resolution instruments [37] with no significant changes in lifetime broadening, experimentally and nor theoretically [38]. According to the many-body picture, the photon energy, should change by the same amount as the change in 
the excitation energy of the incident beam so that inelastic scattering structures sustain constant energy losses, and follow the elastic peak on the emitted-photon energy scale. Second-order perturbation theory for the RIXS process leads to the Kramers-Heisenberg formula for the resonant X-ray scattering amplitude. Using this starting point RIXS has been analyzed in periodic solids as a momentum conserving process, suggesting that it can be used as a novel "band-mapping" technique in and diamond and graphite [39-41] and collective excitations in the strong correlated materials $[42,43]$.
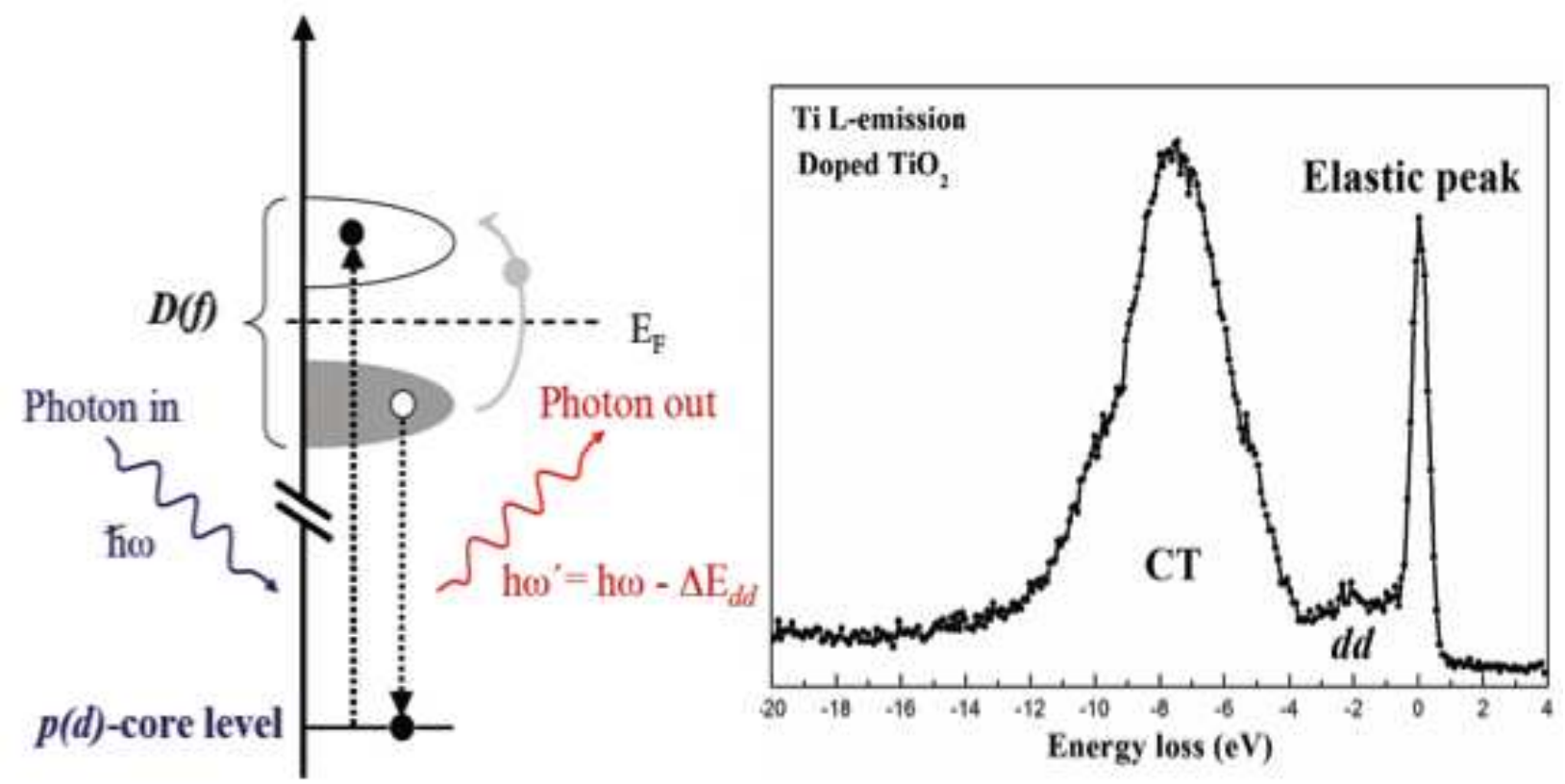

Fig. 3. (a) Schematic 2p-3d RIXS process. (b) Ti L-emission spectrum of doped $\mathrm{TiO}_{2}$.

The schematics in Fig. 3 present the principles of RIXS. As shown in Fig. 3(a), RIXS is a second optical process. In the case of Transition Metal (TM) L-edges, it is the consequences that the core-electron (2p) transit into conduction band (3d) and left excited core-hole behind. Subsequently, the $2 \mathrm{p}$ core holes will be refilled by irradiation from either the same energy level of excited electron or other transition allowed shallower levels such as d-d and Charge Transfer (CT) states. Former will give us a sharp feature in RIXS spectrum that has exactly the same energy as incident photon energy (called elastic peak with zero energy loss) as an example for doped $\mathrm{TiO}_{2}$ RIXS spectrum shown in Fig. 3(b). On the other hand, latter will gives the features with energy loss compare to the incident photon energy (called inelastic peak). The energy loss features are usually corresponding to $d$ - $d$ excitations and Ligand-Metal charge transfer 
excitations. The value of energy loss $d-d$ excitation features can provide the direct information on $3 \mathrm{~d}$ orbital splitting under the crystal field effect (10Dq). Many of the topics had shown the $d-d$ excitation features in RIXS for most of the transition metal complex, for instance in Ti [44], Mn [45], Co and Ni [46] systems.

The pioneering work in soft X-ray RIXS traces back to early 1990s, and to the work of Rubenson et al. on Si L-edge [47], Dong et al. on Al L-edge [48], and Ma et al. on Carbon [39] they found that the excitation energy dependence in RIXS spectra were strongly correlated to intra-molecular orbital interactions, One of the earlier work for example is that, to investigate electronic transitions within copper atoms in $\mathrm{Sr}_{2} \mathrm{CuO}_{2} \mathrm{Cl}_{2}$ [43], an insulating model compound for the copper based high-temperature superconductors (HTS). Contrary to earlier conjecture, it was found that these transitions have energies that are too high to be directly involved in the electron pairing mechanism for high-temperature superconductivity, the source of which is one of the great unsolved problems of condensed-matter physics. Following the rapid development of high brilliance synchrotron radiation light source this technique has been improved significantly just within this last decade.

The common feature of HTSCs is a set of parallel copper-oxygen planes with each $\mathrm{Cu}^{2+}$ ion surrounded by four oxygen atoms [43]. The $3 \mathrm{~d}$ orbitals of copper are in ground state: $x^{2}-y^{2}$ and excited states: $\mathrm{z}^{2}, \mathrm{xz}, \mathrm{yz}$, and xy. Apply to RIXS experiment, the absorption of an X-ray and the emission of an X-ray result in the excitation of the copper $d$ orbital from the ground state to an excited state with a different orientation. The resulting Raman shift (energy of emitted photon relative to the large elastic scattering peak) and polarization dependence in RIXS spectra give the energies of the transitions and the orientations of the orbitals involved.

Most importantly, this experiment also demonstrated that the core-hole lifetime broadening does not affect the resolution of RIXS as shown in previous studies [49]. It suggests that the fine structure can be resolved when spectrometer resolution allows [50], which has motivated the development of high resolution RIXS instrumentation at synchrotron radiation facilities worldwide. The 1st successful high resolution RIXS spectrograph with 10,000 resolving power at $1000 \mathrm{eV}$ has been at the Swiss Light Source [49], and the other one is at SPring-8 [51] which has achieved 7,000 resolving power. 
Strocov proposed an optical scheme which arranges the two dispersion planes orthogonally [52]. With this scheme, it was suggested that the RIXS map can be obtained in a parallel detection scheme with large throughput by imaging over a finite field on the sample, illuminated with dispersed light. However, the proposed scheme suffers from the fact that the focal length of grazing-incidence X-ray optics varies significantly across a finite object field. Warwick et al. took up the $h v^{2}$ idea and developed an advanced flat-field imaging design using aspheric mirrors in a Wolter geometry. A two-dimensional detector then displays the RIXS map with vertical and horizontal axes mapping the incident $\left(h v_{\text {in }}\right)$ and scattered $\left(h v_{\text {out }}\right)$ photon energies, respectively. The spectrometer is designed to provide a resolving power of $\mathrm{R}=30000$ with a total instrument length of 5 meters. The angular acceptance is $5 \mathrm{mrad}$ (vertical) by 9 mrad (horizontal) [53].

\section{EXPERIMENTS AND IN-SITU RIXS}

Understanding the dynamics at taking place molecular level in materials suitable for applications related to energy conversion and energy storage (e.g. photovoltaics, photocatalysis and battery) in real-time is of great importance in order to further improve their efficiencies and longevity. Moreover, it is even more important to be able to study the same when the specimen is in realworld operational mode under ambient conditions. This has however long been impeded given the ultra-high vacuum conditions typically required by soft X-ray spectroscopy. The introduction of the liquid cell (has evolved as a result of intense multidisciplinary collaboration at Advanced Light Source, Lawrence Berkeley National Laboratory over the last decade) has opened many new and exciting avenues for in-situ/operando studies of e.g. electrochemical cell that was not possible before.

These cells are composed of a polyether-ether ketone (PEEK) body separated from the otherwise UHV vacuum chamber by a $100 \mathrm{~nm}$ thick $\mathrm{Si}_{3} \mathrm{~N}_{4}$ membrane window (typically $1 \mathrm{~mm} \times 1 \mathrm{~mm}$ ) to attain UHV compatibility, and enable spectroscopic studies of liquid and gas samples, especially solid/liquid and solid/gas interfaces under reaction conditions.

While the first generation liquid cell were known as "statics cells" i.e. liquid samples could only be studied without any modification in their immediate surroundings, following further development of the same enabled the "flow cell" which allowed for probing samples under continuous gas/liquid flow. 
Since the photon-in/photon-out RIXS is a second order process, and yield lower signal compared to XAS it requires higher intensity radiation. In the case of in-situ studies, the importance for high intensity radiation and more sensitive detectors becomes even more pronounced due to the $\mathrm{Si}_{3} \mathrm{~N}_{4}$ window separating the surface from the main experimental chamber that is typically under UHV conditions. The $\mathrm{Si}_{3} \mathrm{~N}_{4}$ window typically absorbs $36 \%$ of incoming photon at oxygen $\mathrm{K}$-edge (about 530eV), and absorbs an additional $36 \%$ of the emitting (outcoming) photons. However, the optical transparency of the membrane window can be further optimized (i.e. enhanced) upon alternating its chemical composition to allow for higher transmission of the incoming and emitted signal. For instance, the transparency of the window strongly depends its materials properties, so various materials (e.g. Si, $\mathrm{SiC}$ etc.) of membrane window can be selected for different experiments.

The introduction of the electrochemical flow cell has brought new and exciting opportunities in the field of battery research as we are now able to project the local electronic properties of the electrodes in complete electrochemical cell in-operando, and investigate the evolution in the same upon repetitive charge/discharge cycles.

Fig. 4 presents the principle design and the key features of these in-situ cells developed at Lawrence Berkeley National Laboratory. The static liquid cell, Fig. 4(a) uses a thin membrane window to attain compatibility with UHV conditions of the fluorescence spectrometer and synchrotron radiation beamline. The synchrotron radiation enters the liquid cell through a 100 nm thick silicon nitride $\left(\mathrm{Si}_{3} \mathrm{~N}_{4}\right)$ window and the emitted X-rays exit through the same window. The membrane window opening is used to be $1 \mathrm{~mm} \times 1 \mathrm{~mm}$ in order to hold the liquid in a vacuum condition which is required to perform soft X-ray experiments. Furthermore, as shown in Fig. 4(b) an electrochemical static liquid cell embedded with three electrodes is developed for in-situ soft X-ray spectroscopy experiments. This design allows us to perform in-situ/inoperando electrochemistry X-ray spectroscopy measurements.

There also developments on the liquid flow cells. For our design in Fig. 4(c), the central part of the flow liquid cell is similar to the earlier static cell shown in Fig. 4(b), while liquid flow allows a sample refresh in order to eliminate the X-ray induced sample damage problem [54]. It also allows changing the liquid conditions in regards to the solvent concentration, $\mathrm{pH}$, and 
temperature during soft X-ray spectroscopic measurements. It was designed to allow the liquid samples being refreshed in the rate of 50-200 nl/s. And electrode contacts were added to the liquid cells, so that the in-situ/operando soft X-ray spectroscopy experimental study of electrochemistry became possible $[16,18,19,55,56]$. Finally, a four-units high temperature gas cell is also been developed for in-situ catalyst X-ray spectroscopy in Fig. 4(d) [57]. These cells are also used on BL6.3.1.2 and BL8.0.1 at the ALS [58]. In-situ soft X-ray spectroscopy study of liquids has attracted a lot of attentions, and there have been a number of efforts in dealing with molecular liquids in UHV condition [59-61]. Nowadays, since the in-situ X-ray spectroscopies are providing valuable information in chemical reactions in energy materials. The researches regarding in-situ X-ray spectroscopy is intensify activated in the synchrotron radiation facilities all over the world. Hence, many of the active groups delicate to develop the proper cells to accomplish the UHV compatible in-situ environments.
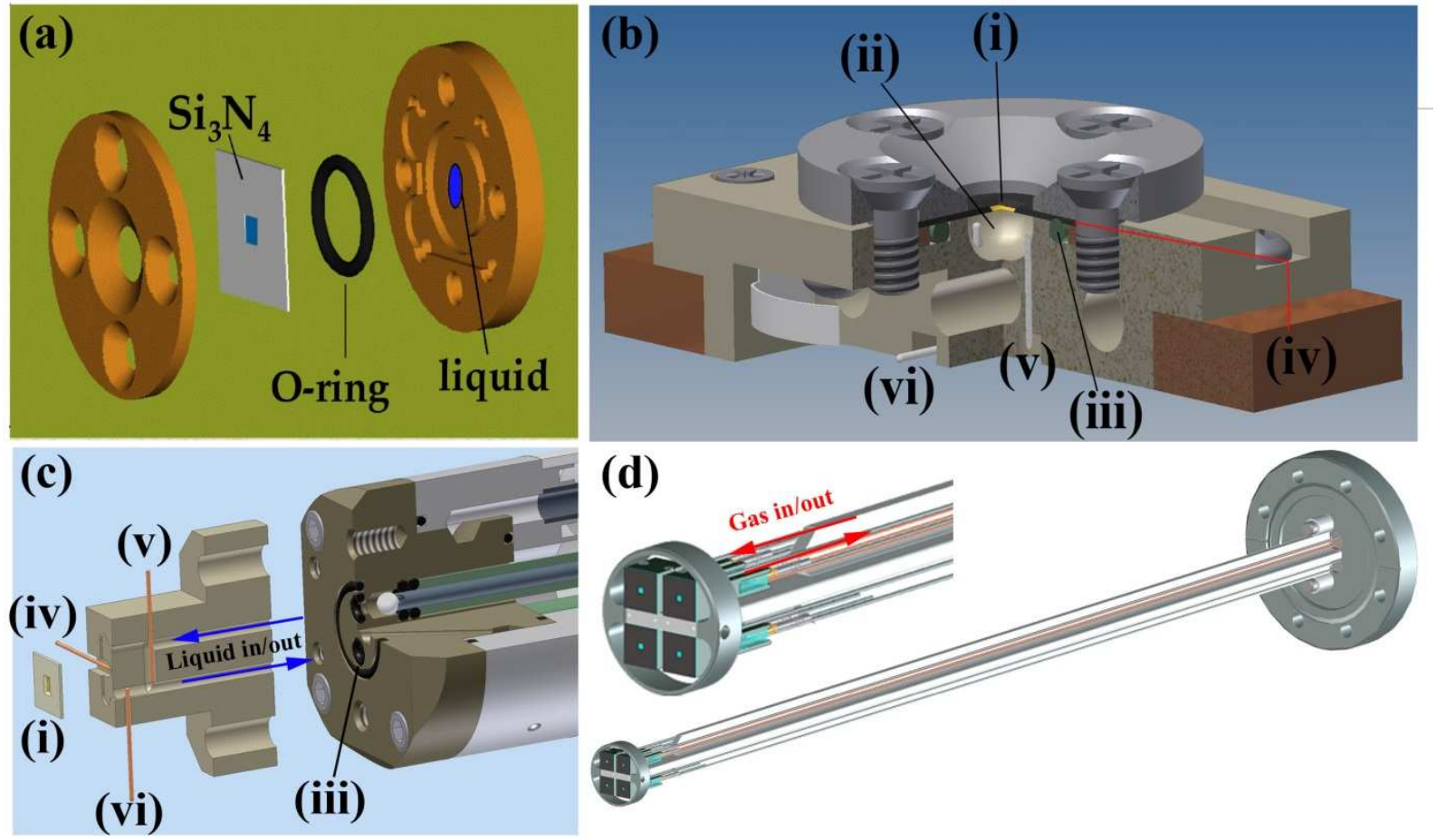

Fig. 4. (a) Static liquid cell. [Ref. 54] (b) Electrochemical static liquid cell (c) electrochemical flow liquid cell [Ref. 55] and (d) Gas cell. Note: (i) $\mathrm{Si}_{3} \mathrm{~N}_{4}$ membrane, (ii) liquid reservoir, (iii) O-ring, (iv) working electrode. (v) counter electrode, and (vi) reference electrode respectively.

The in-situ cells have widely been used to the in-situ soft X-ray emission spectroscopic studies of wet systems, e.g. the first RXES experiments of liquid water [62] and mixtures of 
liquid methanol and water [63]. In addition, soft X-ray emission spectroscopy has also established a firm interpretation for the unusual thermodynamic properties of molecular liquids $[64,65]$.

Growing environmental concerns have renewed the interest in the catalytic process to synthesize cleaner chemical fuels from syngas. Catalysis is a powerful technique for developing chemical processes to make efficient use of energy and raw materials, while achieving the minimal impact on the environment. There have been extensive studies of the catalytic activity and selectivity towards different reactions of interest in Co NP catalysis (Fischer-Tropsch, Water-Gas Shift Reaction, CO oxidation, etc.) [57, 66-69]. The experimental findings provide new insights at the fundamental scientific level that can subsequently be transferred to the industrial catalytic applications [70-76].

\section{IN-SITU/OPERANDO RXES AND RIXS STUDIES OF ENERGY MATERIALS}

Advances in the synthesis of nanoparticles with well-defined size distribution, and controlled geometries have generated great interest for in-situ studies in light of the potential to create novel materials with tailored physical and chemical properties that arise from quantum confinement effects and from the increasing fraction of surface atoms (surface-to-volume ratio) with unique bonding and geometrical configurations $[77,78]$.

One of the flow liquid cell example is that Fuchs et al. has developed a well temperature controlled flow liquid cell and published a series of RXES experiments in Hydrogen bonding environment of $\mathrm{D}_{2} \mathrm{O} / \mathrm{H}_{2} \mathrm{O}$ between solid and liquid phases. Nagasaka et al. have also designed an XAS transmission mode flow liquid cell not like previous mentioned flow cells that are collected the XAS signal from outgoing photons (TFY) [79]. By controlling the thickness of liquid sample they had obtained Water O K-edge XAS spectra without the saturation/self-absorption effects that always happened in typical TFY mode. And another type of and also the other flow liquid cells [80-83] and liquid jets were developed in the different research groups worldwide [84-88]. Recently, Asakura and et al. have also developed an in-situ X-ray spectroscopy electrochemical cell and successfully monitoring the Li-ion extraction/insertion reaction in $\mathrm{LiMn}_{2} \mathrm{O}_{4}$ cathode material [89]. 
Cobalt nanocrystals display a wealth of important size-dependent properties: structural-, magnetic-, electronic-, and catalytic properties. Nanostructutred cobalt have extensively been studied for their applicability in photoelectrochemical reactions that convert carbon dioxide and water into fuel molecules (hydrogen, methane gas, or simple alcohols) in a single, integrated device fueled by solar power (a.k.a. artificial photosynthesis) [90, 91]. However, challenges in synthesizing isolated cobalt nanocrystals include to overcome the large attractive forces between the nanoparticles due to surface tension and van der Waals interactions that aggregates the particles $[92,93]$.

Liu et al. have presented soft X-ray in-situ XAS and RIXS studies on the evolution in the electronic structure of Co nanoparticles (suspended in 1,2-dichlorobenzene) as a function of increasing average particle size $(3-9 \mathrm{~nm})$, see Fig. 5A [94]. The authors reported a sharp absorption peak in the absorption spectra (not shown in this review) of the Co nanoparticles with average particles size of: $3,4,5,6$, and 9 nanometers which was found to be in associated with the ligand molecules, and its intensity increasing upon reducing the nanocrystal size. In the bottom of Fig. 5A, in comparison with $\mathrm{CoO}$ and $\mathrm{CoCl}_{2}$ references, the RIXS (energy-loss) features due to $d$-d and to charge-transfer excitations of ligand molecules have been identified. The study reveals the local symmetry of the cobalt nanoparticles surface with a dynamic interaction between Co nanoparticles and surfactant + solvent molecules [94].
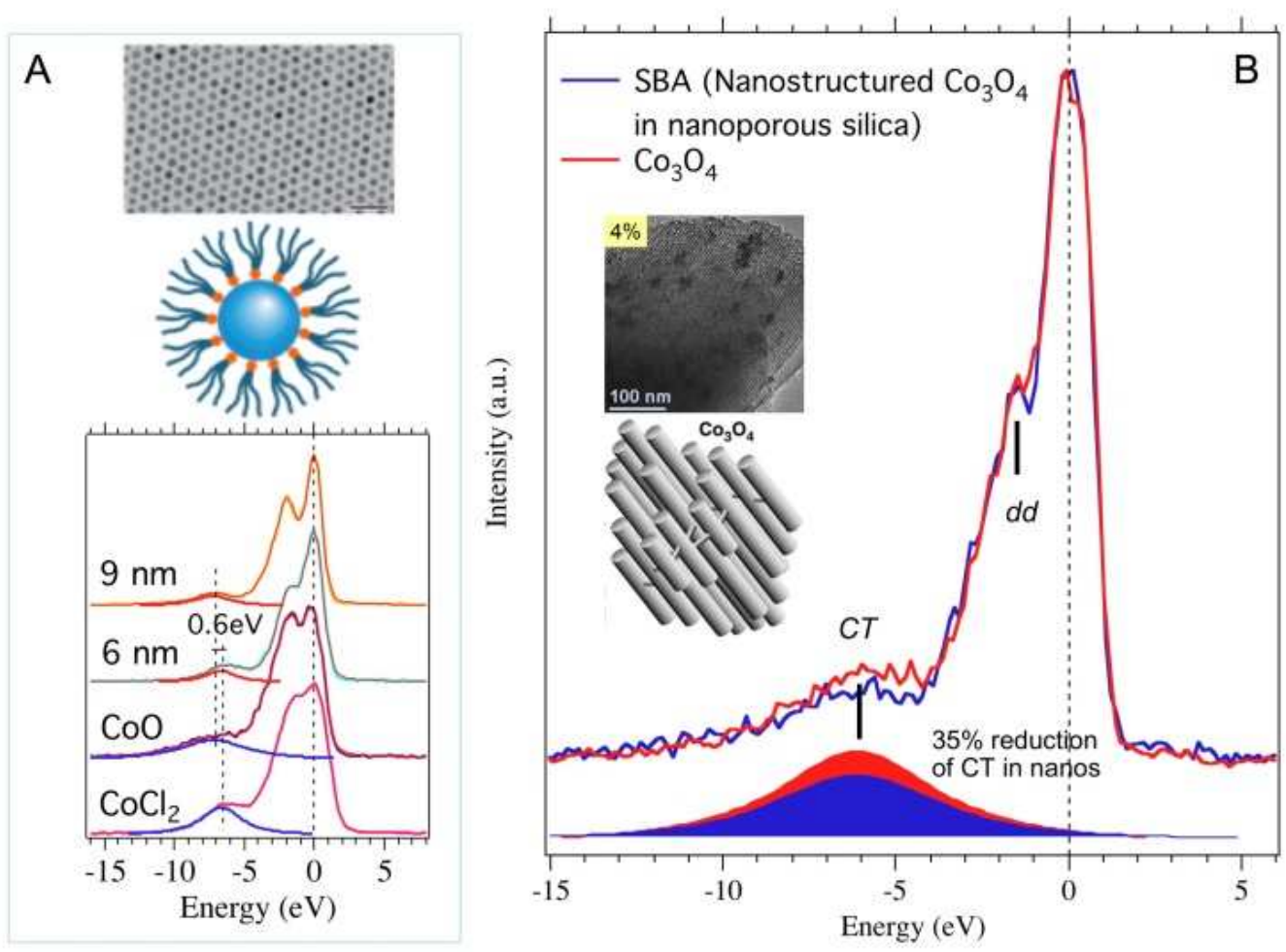
Fig. 5A. upper: TEM image of Co NPs, schematic drawing of Co NPs in connection to the surfactants in the middle and RIXS spectra of Co NPs with references in comparison [Ref. 94]; B. RIXS spectra of $\mathrm{Co}_{3} \mathrm{O}_{4}$ in micro dimension (red curve) and nanostructured $\mathrm{Co}_{3} \mathrm{O}_{4}$ in nano porous silica SBA-15 [Ref. 97], insert: TEM image of $\mathrm{Co}_{3} \mathrm{O}_{4}$ NPs in SBA-15 and schematic drawing of $\mathrm{Co}_{3} \mathrm{O}_{4}$ NPs without SBA-15.

The electronic structure of these materials is determined in part by using synchrotron based near-edge and extended X-ray absorption spectroscopy. Recent soft X-ray developments involving high-efficiency emission spectrographs, ambient-pressure photoemission spectroscopy, and in-situ measurement techniques provide a better indication of the oxidation state, symmetry, electronic structure, and charge-transfer processes in the complexes involved.

RIXS were used to reveal the charge-doping mechanism in the BNCO/CCO superconducting superlattices [95], It was shown that the CT-feature in the RIXS spectra presented an evidence of charge transport from the charge reservoir layer to the infinite layer through a pyramid of holedoped oxides. It was suggested that the superconductivity and both the interaction of the electrons (known as electron correlation) and charge transfer are strongly linked within the superlattices.

It has been argued that cobalt oxide $\left(\mathrm{Co}_{3} \mathrm{O}_{4}\right)$ particles in the nano regime are more functional catalysts in photocatalytic reactions for decomposition of water molecules into oxygen and hydrogen than cobalt oxide in the micrometer regime [96]. RIXS allows determination of the $d-d$ and charge transfer (CT) excitations of $\mathrm{Co}_{3} \mathrm{O}_{4}$ microcrystalline powder and nanostructured $\mathrm{Co}_{3} \mathrm{O}_{4}$ in nanoporous silica [97] as shown in Fig. 5B. The insert is the TEM image of $\mathrm{Co}_{3} \mathrm{O}_{4} \mathrm{NPs}$ in SBA-15 and schematic drawing of $\mathrm{Co}_{3} \mathrm{O}_{4}$ NPs without SBA-15. The $\mathrm{Co}_{3} \mathrm{O}_{4}$ NPs loading in SBA-15 is about 5-8 wt\%. There is a significant change in the intensity of CT-feature for the RIXS spectra of $\mathrm{Co}_{3} \mathrm{O}_{4}$ in micro size and nano porous silica SBA-15. It is illustrated in blue in Fig. 5B (the nano $\mathrm{Co}_{3} \mathrm{O}_{4}$ in porous silica $\left.\mathrm{SBA}-15\right)$ and in red $\left(\right.$ micro $\left.\mathrm{Co}_{3} \mathrm{O}_{4}\right)$ filled pattern, which shows the evidence of the CT-process between the nano $\mathrm{Co}_{3} \mathrm{O}_{4}$ particles and the nanoporous silica support. 


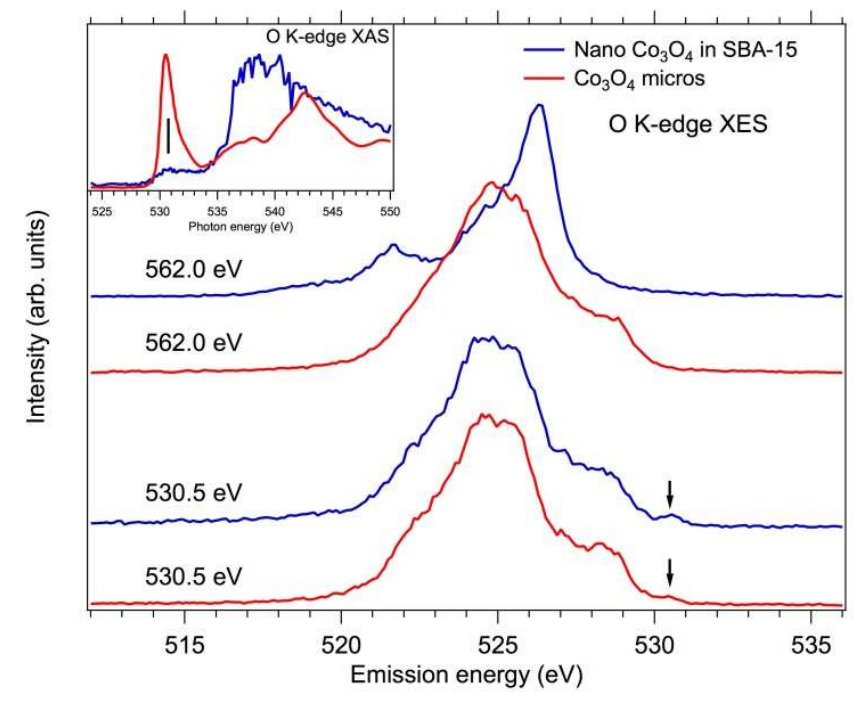

Fig. 6. O K-edge XES spectra of $\mathrm{Co}_{3} \mathrm{O}_{4}$ of micro size and nanostructured size in nano porous silica SBA-15 recorded at $530.5 \mathrm{eV}$ (resonant excitation) and $562.0 \mathrm{eV}$ (non-resonant excitation), insert: XAS spectra of $\mathrm{Co}_{3} \mathrm{O}_{4}$ in micro size and nano porous silica SBA-15.

Fig. 6 presents a comparison between the O K-edge XAS (inset), and XES spectra of resonant and non-resonant excitations of micro $\mathrm{Co}_{3} \mathrm{O}_{4}$ and $\mathrm{Co}_{3} \mathrm{O}_{4}$ nanoparticles in nanoporous silica (SBA-15). As evident, the shows O 1s spectral features of the two oxide complexes differ distinctly and the XAS spectral profile is dramatically different because the sample of nano $\mathrm{Co}_{3} \mathrm{O}_{4}$ in SBA-15 has major contribution (more than $92 \mathrm{wt} \%$ ) from silica $\left(\mathrm{SiO}_{2}\right)$. It explains that the normal XES spectrum of nano $\mathrm{Co}_{3} \mathrm{O}_{4}$ in SBA-15 presents basically the XES spectral shape of $\mathrm{SiO}_{2}$. The only common XAS feature for these two samples is the absorption peak at $530.5 \mathrm{eV}$, thus the RXES spectral profile excited at $530.5 \mathrm{eV}$ is the much alike due to the largely enhancement of RXES to the selected chemical spices. It is a clear demonstration of the chemical sensitivity for RXES.

Although $\mathrm{TiO}_{2}$ is one of the most widely studied oxide material for application in nextgeneration photovoltaics, and photocatalysis, its wide band gap (ca. $3.0-3.2 \mathrm{eV}$ ) remains to be of major concern since it impedes the performance of the oxide in the visible wavelength range (at which maximum radiation is emitted). In addition, charge carrier separation upon photoexcitation is another pressing challenge that needs to be overcome in order to prevent photoelectrons from re-combining with their associated holes. Among the many studies that have been designed to address these issues, construction of heterostructures to improve the 
photoactivity of $\mathrm{TiO}_{2}$ holds great promise $[98,99]$ and using quantum dots sensitized structures [100-102].

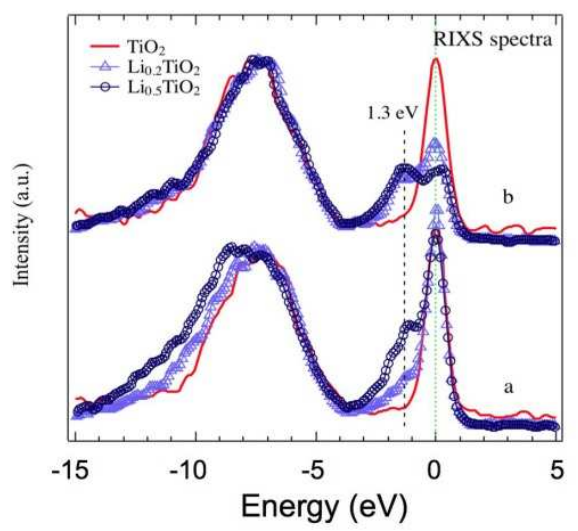

Fig. 7. RIXS spectra of $\mathrm{Li}_{\mathrm{x}} \mathrm{TiO}_{2}$ produced by the electrochemical insertion reaction [Ref. 105].

In order to understand the charge transport in the solar energy conversion process, we review another exciting and emerging field of application where the applicability of nanostructured $\mathrm{TiO}_{2}$ has been explored in Li-ion batteries [103]. Here a $\mathrm{Li}_{\mathrm{x}} \mathrm{TiO}_{2}$ electrode is composed of interconnected nanocrystallites forming a nanoporous structure with an extremely large inner surface allowing for electrochemical reactions to take place throughout the entire volume of the electrode. High charging capacities have been reported [103, 104] when lithium is inserted into nanoporous anatase titanium dioxide. Fig. 7 presents the RIXS spectra of both intrinsic, and Li inserted $\mathrm{TiO}_{2}$ [105]. The inelastic scattering features of the intrinsic oxide in energy -15 to $-5 \mathrm{eV}$ have been attributed to charge-transfer excitations with electronic configuration $3 \mathrm{~d}^{1} \underline{L}^{-1}$ of $\mathrm{Ti}$ where $\underline{L}^{-1}$ represent a ligand hole on $\mathrm{O} 2 \mathrm{p}$ orbitals [106]. The low energy-loss features at $1.3 \mathrm{eV}$ in the RIXS spectra of the Li inserted $\mathrm{TiO}_{2}$, appearing within $\mathrm{t}_{2 \mathrm{~g}}$ bands due to the $d$ - $d$ excitations, indicate on the presence of $\mathrm{Ti}^{3+}$ states. And the intensity of RIXS feature at $1.3 \mathrm{eV}$ increases with the amount of $\mathrm{Li}$ being inserted to $\mathrm{TiO}_{2}$ nanoparticles, which is a result of charge transfer from Li-ion to $\mathrm{Ti} 3 \mathrm{~d}$-states of $\mathrm{TiO}_{2}$. These experimental findings suggest the strong electron correlation in the anatase $\mathrm{TiO}_{2}$ introduced by $\mathrm{Li}$ insertion.

Fig. 8(A) presents the energy diagram of narrow band gap CdSe quantum dots (serving a photosensitizer) - $\mathrm{TiO}_{2}$ heterostructures, which introduces an alternative route, to doping, to (i) enhance the photoactivity of $\mathrm{TiO}_{2}$ in the visible wavelength range, and (ii) to reduce the electronhole recombination probability as the $\mathrm{CdSe} / \mathrm{TiO}_{2}$ interface introduces a spatial charge separation 
barrier [100-102]. However, to further improve the performance of QDs sensitized $\mathrm{TiO}_{2}$ systems, the details of the vectorial charge separation across the $\mathrm{QDs} / \mathrm{TiO}_{2}$ interfaces need to be better understood at a fundamental level.
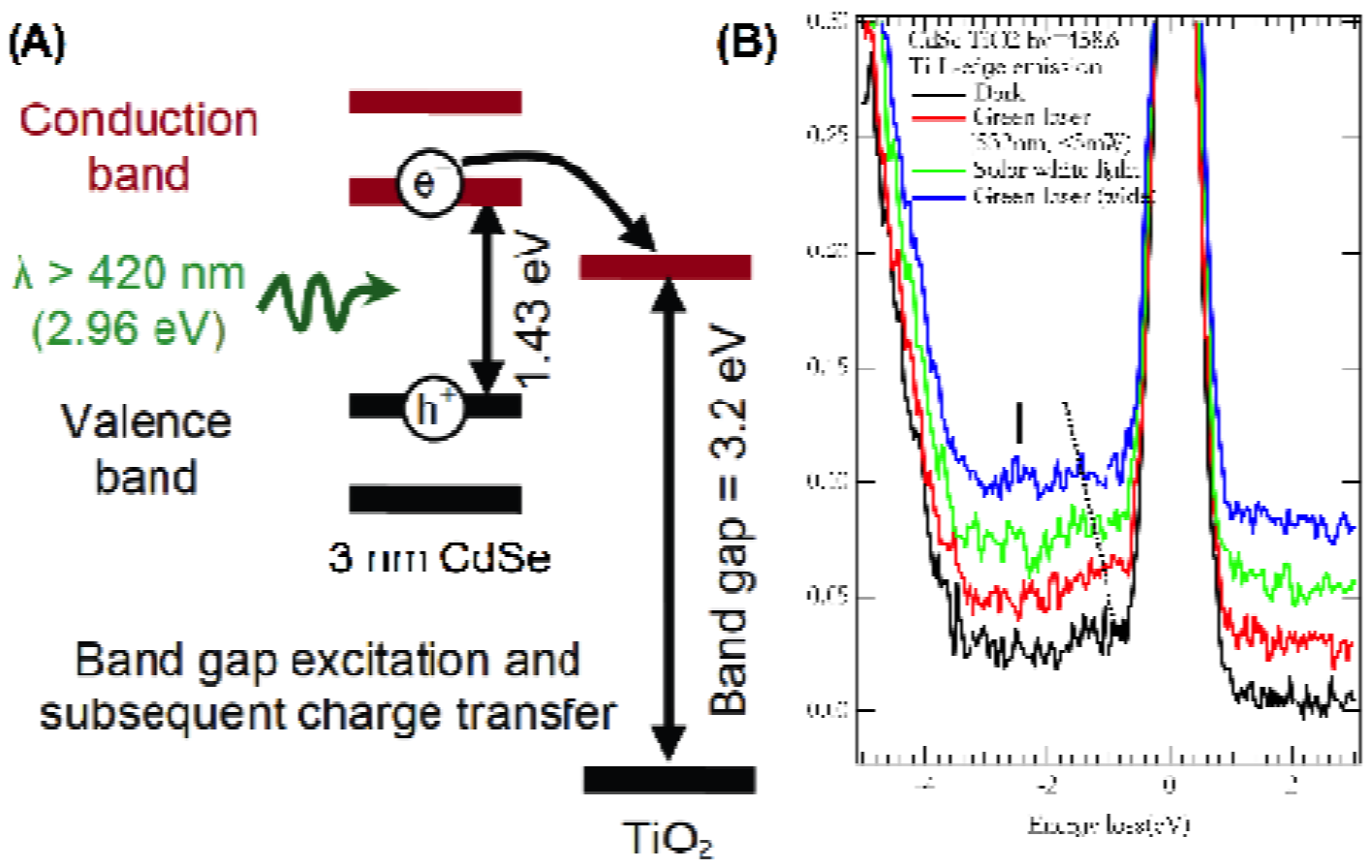

Fig. 8. (A) shows the energy diagram of CdSe QDs in relation to the energy band levels of $\mathrm{TiO}_{2}$. $\mathrm{TiO}_{2}$ has a bandgap of $3.2 \mathrm{eV}$. When using a light of $420 \mathrm{~nm}(2.96 \mathrm{eV})$, only the semiconductor CdSe QDs can be excited. It is expected to see a charge (electron) transfer happening from the excited CdSe QDs to the Ti 3d states of $\mathrm{TiO}_{2}$; (B) RIXS spectra of CdSe QDs sensitized $\mathrm{TiO}_{2}$ nanoparticles with light on/off, respectively. [113]

Using the established the RIXS fingerprint of $\mathrm{Li}$ inserted $\mathrm{TiO}_{2}$, we can now turn to the RIXS study of the CdSe QDs sensitized $\mathrm{TiO}_{2}$ nanoparticles Fig. 8(B). Initially, the RIXS spectrum of CdSe QDs sensitized $\mathrm{TiO}_{2}$ (red curve) shows a single elastic peak at $462.5 \mathrm{eV}$ without RIXS feature which indicates $\mathrm{Ti}$ is in 4+ oxygen state. After turn on the $420 \mathrm{~nm}$ light, CdSe QDs experiences a band gap excitation, but the light energy is too low $(2.96 \mathrm{eV})$ for bandgap excitation of $\mathrm{TiO}_{2}$ (bandgap $=3.2 \mathrm{eV}$ ). The RIXS feature appears in the spectrum of CdSe QDs sensitized $\mathrm{TiO}_{2}$ (green curve) indicating the appearing of $\mathrm{Ti}^{3+}$ state, which is a result of charge transfer from the bandgap excited CdSe QDs to Ti 3d-states of $\mathrm{TiO}_{2}$.

\section{PERSPECTIVES OF IN-SITU/OPERANDO RXES AND RIXS IN ENERGY SCIENCE}


Complex phenomena in condensed matter continue to be a major theme of physics. Some of these, such as the quantum Hall effect, magnetism and high-Tc superconductivity, have the potential to fundamentally change our view of the physical world and significantly impact the technology. The complex physics of these novel materials, driven by interplay between different degrees of freedom, calls for combining together different tools and higher resolution to reach a more complete understanding of their physical and chemical properties. High-resolution RIXS has played, and will continue to play a leading role in the future in pushing the frontier of this important field [10, 50].

The properties of materials are closely related to the energies for the low-lying excited states. RIXS probes these directly through the energy transfer during scattering process. Soft X-rays with the photon energy tuned to an electronic resonance have the unique advantage of high chemical and site selectivity. RIXS is not only sensitive to a wide range of elementary excitations like crystal-field, inter-band and charge-transfer excitations of electronic nature, but also to magnetic excitations and phonons in solids [107-110] and vibrational excitations in molecular systems $[111,112]$. Thus, dispersion of collective excitations in condensed matter and the symmetry of low-energy excitations in molecular systems can be mapped out. 


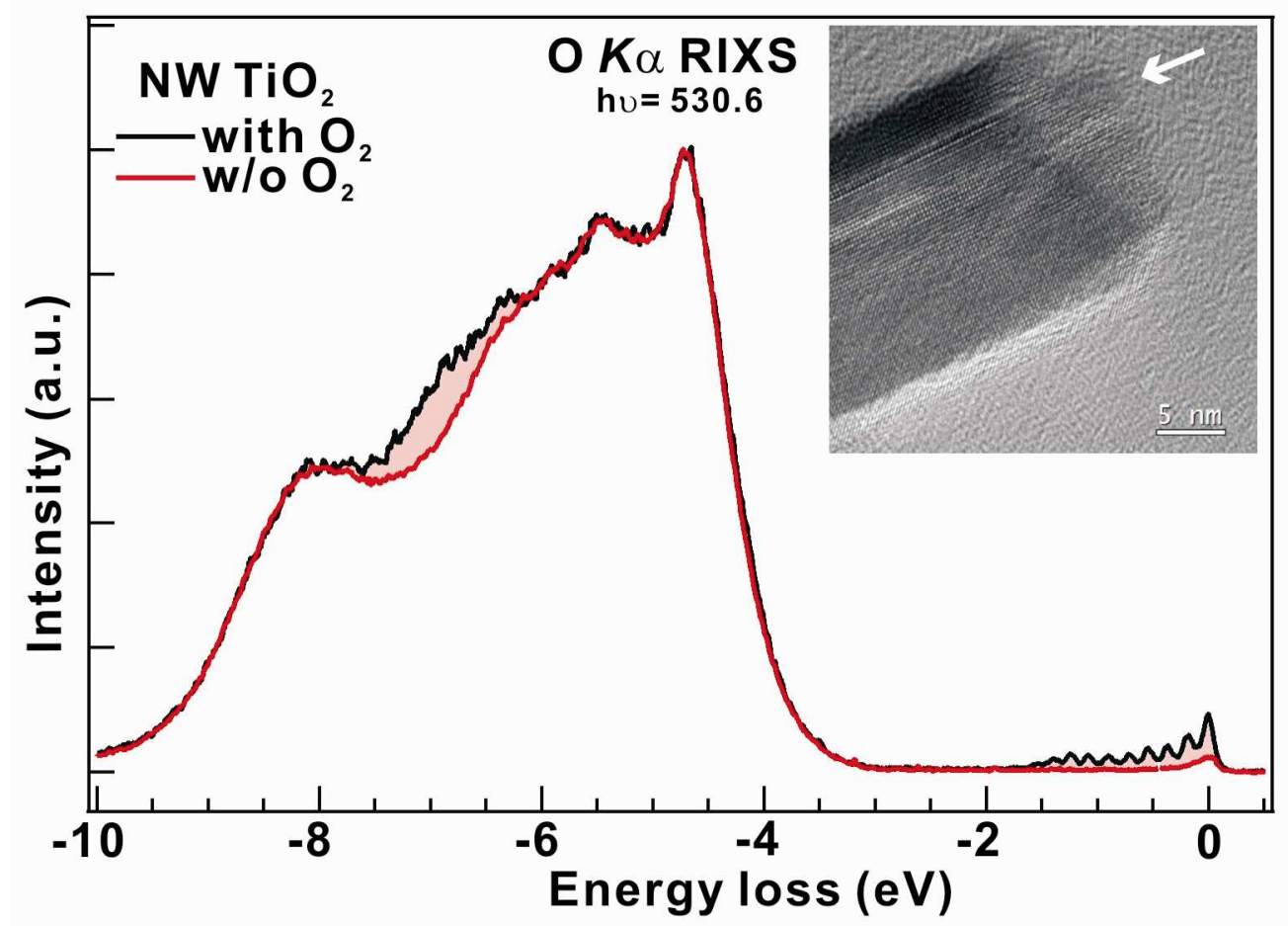

Fig. 9. RIXS spectra of with and without $\mathrm{O}_{2}$ adsorption on $\mathrm{TiO}_{2} \mathrm{NWs}$. The inset (TEM image) illustrates the lattice structure and dimension of $\mathrm{TiO}_{2}$ NWs [Reproduced from Ref. 113].

Fig. 9 presents the difference in the $\mathrm{O}$ K-edge RIXS of intrinsic and $\mathrm{O}_{2}$ absorbed $\mathrm{TiO}_{2}$ nanowires (NWs) (recorded at beamline 7.0LSU of SPring-8) [113]. As evident, the RIXS spectra have large contribution of $\mathrm{O}$ of $\mathrm{TiO}_{2}$ nanowires, while the difference between with $\mathrm{O}_{2}$ and without $\mathrm{O}_{2}$ spectra comes from the RIXS spectrum of $\mathrm{O}_{2}$ molecules. At resonant excitation $(530.6 \mathrm{eV})$ we observe 11 distinct vibrational excitations in energy loss from -2 to $0 \mathrm{eV}$ regions, spanning an energy range of close to $2 \mathrm{eV}$.

Recent advances in instrumental and theoretical development have led to significant advances in soft X-ray RIXS. The power of this technique has been widely recognized, and interest for using this technique has been steadily growing into other fields of research than traditional materials science. To meet the continuous increase in the interest and demand for this technique, new and more advanced RIXS facilities are under development at synchrotron facilities around the world (e.g. NSLS-II, Diamond, MAX IV, TPS, ALS, and BESSY-II) that will offer unprecedented energy and momentum resolution, and enhanced throughput, to further expand this research frontier. 
A new beamline: Advanced Materials Beamline for Energy Research (AMBER), is currently under development at the Advanced Light Source that will comprise a high throughput monochromator with dedicated in-situ/operando soft X-ray spectroscopy end-stations, and where in-situ RIXS will be a major part of it. AMBER will be a high-intensity, wide-energy-range (250-2500 eV) beamline equipped with in situ sample preparation and control systems as well as a high throughput emission spectrograph, ambient pressure electron energy analyzer (APXPS) and user-friendly in-situ scanning transmission X-ray microscope (in-situ STXM). The choice of detection system will allow the study of surfaces, interfaces, and bulk electronic structure of novel inorganic and biological/organic systems. The combination of absorption spectroscopy that measures unoccupied conduction bands and emission spectroscopy that gives information about the occupied valence bands, AMBER will be uniquely equipped for a better understanding of the properties of energy materials and the tailoring of these properties for renewable energy applications.

In summary, we have presented a few examples of RXES and RIXS applications in materials science to illustrate the chemical and interfacial sensitivity of the soft X-ray spectroscopy techniques. The RXES and RIXS studies on a variety of nanostructured systems have yielded characteristic fingerprints of information on the geometric structure, chemical bonding and different charge and spin states. The in-situ/operando capability of the characterization tools offers unique perspectives not only in the research areas of energy materials and devices, but also to a broader science community.

\section{ACKNOWLEDGEMENTS}

The RIXS instrument development and experimental work has been largely benefit from the collaboration with many co-workers from the Department of Physics, Uppsala University, the ALS, CSD, MSD, and PBD of Lawrence Berkeley National Laboratory, who can be found in the references of this review. The work at the Advanced Light Source is supported by the Director, Office of Science, Office of Basic Energy Sciences, of the U.S. Department of Energy under Contract No. DE-AC02-05CH11231. MK acknowledges additional DOE funding support under Contract No. DE-SC0006931 


\section{REFERENCES}

[1] G.W. Crabtree, N.S. Lewis, Solar energy conversion, Physics Today, 60 (2007) 37-42.

[2] J.R. Bolton, S.J. Strickler, J.S. Connolly, Limiting and realizable efficiencies of solar photolysis of water, Nature, 316 (1985) 495-500.

[3] A.J. Bard, Photoelectrochemistry, Science, 207 (1980) 139-144.

[4] J.R. Bolton, Solar Fuels, Science, 202 (1978) 705-711.

[5] M. Kapilashrami, Y. Zhang, Y.-S. Liu, A. Hagfeldt, J.-H. Guo, Probing the Optical Property and Electronic Structure of $\mathrm{TiO}_{2}$ Nanomaterials for Renewable Energy Applications, Chemical Reviews, 114 (2014) 9662-9707.

[6] E.J. Nordgren, S.M. Butorin, L.C. Duda, J.-H. Guo, J.E. Rubensson, Soft X-Ray Fluorescence Spectroscopy for Materials Science and Chemical Physics, 12 (2002) 517-572.

[7] E.Z. Kurmaev, R.G. Wilks, A. Moewes, L.D. Finkelstein, S.N. Shamin, J. Kuneš, Oxygen x-ray emission and absorption spectra as a probe of the electronic structure of strongly correlated oxides, Physical Review B, 77 (2008) 165127.

[8] C. Parks Cheney, P. Vilmercati, E.W. Martin, M. Chiodi, L. Gavioli, M. Regmi, G. Eres, T.A. Callcott, H.H. Weitering, N. Mannella, Origins of Electronic Band Gap Reduction in $\mathrm{Cr} / \mathrm{N}$ Codoped $\mathrm{TiO}_{2}$, Physical Review Letters, 112 (2014) 036404.

[9] F. Gel'mukhanov, H. Ågren, Resonant inelastic x-ray scattering with symmetry-selective excitation, Physical Review A, 49 (1994) 4378-4389.

[10] A. Kotani, S. Shin, Resonant inelastic x-ray scattering spectra for electrons in solids, Reviews of Modern Physics, 73 (2001) 203-246.

[11] M. van Veenendaal, Polarization Dependence of L- and M-Edge Resonant Inelastic X-Ray Scattering in Transition-Metal Compounds, Physical Review Letters, 96 (2006) 117404.

[12] L. Braicovich, M. Moretti Sala, L.J.P. Ament, V. Bisogni, M. Minola, G. Balestrino, D. Di Castro, G.M. De Luca, M. Salluzzo, G. Ghiringhelli, J. van den Brink, Momentum and polarization dependence of single-magnon spectral weight for $\mathrm{Cu} \square \mathrm{L}_{3}$-edge resonant inelastic x-ray scattering from layered cuprates, Physical Review B, 81 (2010) 174533.

[13] T. Inami, T. Fukuda, J. Mizuki, S. Ishihara, H. Kondo, H. Nakao, T. Matsumura, K. Hirota, Y. Murakami, S. Maekawa, Y. Endoh, Orbital excitations in $\mathrm{LaMnO}_{3}$ studied by resonant inelastic xray scattering, Physical Review B, 67 (2003) 045108.

[14] J. Stöhr, NEXAFS Spectroscopy, Springer-Verlag Berlin Heidelberg, 25 (1992).

[15] F. de Groot, High-Resolution X-ray Emission and X-ray Absorption Spectroscopy, Chemical Reviews, 101 (2001) 1779-1808.

[16] T.S. Arthur, P.-A. Glans, M. Matsui, R. Zhang, B. Ma, J.-H. Guo, Mg deposition observed by in situ electrochemical Mg K-edge X-ray absorption spectroscopy, Electrochemistry Communications, 24 (2012) 43-46.

[17] A. Benmayza, M. Ramanathan, T.S. Arthur, M. Matsui, F. Mizuno, J.-H. Guo, P.-A. Glans, J. Prakash, Effect of Electrolytic Properties of a Magnesium Organohaloaluminate Electrolyte on Magnesium Deposition, The Journal of Physical Chemistry C, 117 (2013) 26881-26888.

[18] A. Braun, K. Sivula, D.K. Bora, J. Zhu, L. Zhang, M. Grätzel, J.-H. Guo, E.C. Constable, Direct Observation of Two Electron Holes in a Hematite Photoanode during Photoelectrochemical Water Splitting, The Journal of Physical Chemistry C, 116 (2012) 16870-16875.

[19] J.-J. Velasco-Velez, C.H. Wu, T.A. Pascal, L.F. Wan, J.-H. Guo, D. Prendergast, M. Salmeron, The structure of interfacial water on gold electrodes studied by x-ray absorption spectroscopy, Science, 346 (2014) 831-834.

[20] W. Gudat, C. Kunz, Close Similarity between Photoelectric Yield and Photoabsorption Spectra in the Soft-X-Ray Range, Physical Review Letters, 29 (1972) 169-172. 
[21] J. Jaklevic, J.A. Kirby, M.P. Klein, A.S. Robertson, G.S. Brown, P. Eisenberger, Fluorescence detection of exafs: Sensitivity enhancement for dilute species and thin films, Solid State Communications, 23 (1977) 679-682.

[22] S. Eisebitt, T. Böske, J.E. Rubensson, W. Eberhardt, Determination of absorption coefficients for concentrated samples by fluorescence detection, Physical Review B, 47 (1993) 14103-14109.

[23] L. Tröger, D. Arvanitis, K. Baberschke, H. Michaelis, U. Grimm, E. Zschech, Full correction of the self-absorption in soft-fluorescence extended x-ray-absorption fine structure, Physical Review B, 46 (1992) 3283-3289.

[24] J. Nordgren, N. Wassdahl, Soft x-ray fluorescence spectroscopy using tunable synchrotron radiation, Journal of Electron Spectroscopy and Related Phenomena, 72 (1995) 273-280.

[25] E.J. Nordgren, Soft X-ray emission spectroscopy in the nineties, Journal of Electron Spectroscopy and Related Phenomena, 78 (1996) 25-30.

[26] J.-H. Guo, S.M. Butorin, N. Wassdahl, P. Skytt, J. Nordgren, Y. Ma, Electronic structure of $\mathrm{La}_{2-\mathrm{x}} \mathrm{Sr}_{\mathrm{x}} \mathrm{CuO}_{4}$ studied by soft-x-ray-fluorescence spectroscopy with tunable excitation, Physical Review B, 49 (1994) 1376-1380.

[27] S.M. Butorin, J.H. Guo, N. Wassdahl, P. Skytt, J. Nordgren, Y. Ma, C. Ström, L.G. Johansson, M. Qvarford, Electronic structure of $\mathrm{Bi}_{2} \mathrm{Sr}_{2} \mathrm{CaCu}_{2} \mathrm{O}_{8+\delta}$ and $\mathrm{Tl}_{2} \mathrm{Ba}_{2} \mathrm{CaCu}_{2} \mathrm{O}_{8}$ : Near-O-1s-threshold excitation X-ray fluorescence studies, Physical Review B, 51 (1995) 11915-11923.

[28] J.-H. Guo, S.M. Butorin, N. Wassdahl, J. Nordgren, P. Berastegut, L.G. Johansson, Electronic structure of $\mathrm{YBa}_{2} \mathrm{Cu}_{3} \mathrm{O}_{\mathrm{x}}$ and $\mathrm{YBa}_{2} \mathrm{Cu}_{4} \mathrm{O}_{8}$ studied by soft-x-ray absorption and emission spectroscopies, Physical Review B, 61 (2000) 9140-9144.

[29] P. Glans, K. Gunnelin, P. Skytt, J.H. Guo, N. Wassdahl, J. Nordgren, H. Ågren, F.K. Gel'mukhanov, T. Warwick, E. Rotenberg, Resonant X-Ray Emission Spectroscopy of Molecular Oxygen, Physical Review Letters, 76 (1996) 2448-2451.

[30] P. Skytt, P. Glans, J.-H. Guo, K. Gunnelin, C. Såthe, J. Nordgren, F.K. Gel'mukhanov, A. Cesar, H. Ågren, Quenching of Symmetry Breaking in Resonant Inelastic X-Ray Scattering by Detuned Excitation, Physical Review Letters, 77 (1996) 5035-5038.

[31] J. Nordgren, P. Glans, K. Gunnelin, J.-H. Guo, P. Skytt, C. Såthe, N. Wassdahl, Resonant soft X-ray fluorescence spectra of molecules, Appl Phys A, 65 (1997) 97-105.

[32] J. Redinger, J. Yu, A.J. Freeman, P. Weinberger, Calculated local density X-ray and photoemission spectra for superconducting $\mathrm{La}_{2-\mathrm{x}} \mathrm{M}_{\mathrm{x}} \mathrm{CuO}_{4}$ : Localization of $\mathrm{Cu}-3 \mathrm{~d}$, Physics Letters A, 124 (1987) 463-468.

[33] R.J. Green, D.W. Boukhvalov, E.Z. Kurmaev, L.D. Finkelstein, H.W. Ho, K.B. Ruan, L. Wang, A. Moewes, Room-temperature ferromagnetism via unpaired dopant electrons and $\mathrm{p}$-p coupling in carbon-doped $\operatorname{In}_{2} \mathrm{O}_{3}$ : Experiment and theory, Physical Review B, 86 (2012) 115212.

[34] E.F. Aziz, The solvation of ions and molecules probed via soft X-ray spectroscopies, Journal of Electron Spectroscopy and Related Phenomena, 177 (2010) 168-180.

[35] Y. Horikawa, A. Yoshida, O. Takahashi, H. Arai, T. Tokushima, T. Gejo, S. Shin, The electronic structure of carbonate ion in aqueous solution studied by soft X-ray emission spectroscopy, Journal of Molecular Liquids, 189 (2014) 9-12.

[36] K.M. Lange, M. Soldatov, R. Golnak, M. Gotz, N. Engel, R. Könnecke, J.-E. Rubensson, E.F. Aziz, $\mathrm{X}$-ray emission from pure and dilute $\mathrm{H}_{2} \mathrm{O}$ and $\mathrm{D}_{2} \mathrm{O}$ in a liquid microjet: Hydrogen bonds and nuclear dynamics, Physical Review B, 85 (2012) 155104.

[37] K. Hämäläinen, D.P. Siddons, J.B. Hastings, L.E. Berman, Elimination of the inner-shell lifetime broadening in X-ray-absorption spectroscopy, Physical Review Letters, 67 (1991) 2850-2853.

[38] P.H. Citrin, P.M. Eisenberger, W.C. Marra, T. Åberg, J. Utriainen, E. Källne, Linewidths in x-ray photoemission and x-ray emission spectroscopies: What do they measure?, Physical Review B, 10 (1974) 1762-1765.

[39] Y. Ma, N. Wassdahl, P. Skytt, J. Guo, J. Nordgren, P.D. Johnson, J.E. Rubensson, T. Boske, W. Eberhardt, S.D. Kevan, Soft-X-ray resonant inelastic scattering at the C K edge of diamond, Physical Review Letters, 69 (1992) 2598-2601. 
[40] Y. Ma, P. Skytt, N. Wassdahl, P. Glans, J. Guo, J. Nordgren, Core excitons and vibronic coupling in diamond and graphite, Physical Review Letters, 71 (1993) 3725-3728.

[41] J.A. Carlisle, E.L. Shirley, E.A. Hudson, L.J. Terminello, T.A. Callcott, J.J. Jia, D.L. Ederer, R.C.C. Perera, F.J. Himpsel, Probing the Graphite Band Structure with Resonant Soft-X-Ray Fluorescence, Physical Review Letters, 74 (1995) 1234-1237.

[42] S.M. Butorin, J.-H. Guo, M. Magnuson, P. Kuiper, J. Nordgren, Low-energy d-d excitations in MnO studied by resonant x-ray fluorescence spectroscopy, Physical Review B, 54 (1996) 4405-4408.

[43] P. Kuiper, J.-H. Guo, C. Såthe, L.C. Duda, J. Nordgren, J.J.M. Pothuizen, F.M.F. de Groot, G.A. Sawatzky, Resonant X-Ray Raman Spectra of $\mathrm{Cu}$ dd Excitations in $\mathrm{Sr}_{2} \mathrm{CuO}_{2} \mathrm{Cl}_{2}$, Physical Review Letters, 80 (1998) 5204-5207.

[44] M. Matsubara, T. Uozumi, A. Kotani, Y. Harada, S. Shin, Polarization Dependence of Resonant XRay Emission Spectra in $3 \mathrm{~d}_{\mathrm{n}}$ Transition Metal Compounds with $\mathrm{n}=0,1,2,3$, Journal of the Physical Society of Japan, 71 (2002) 347-356.

[45] G. Ghiringhelli, M. Matsubara, C. Dallera, F. Fracassi, A. Tagliaferri, N.B. Brookes, A. Kotani, L. Braicovich, Resonant inelastic x-ray scattering of $\mathrm{MnO}: \mathrm{L}_{2,3}$ edge measurements and assessment of their interpretation, Physical Review B, 73 (2006) 035111.

[46] A. Kotani, M. Matsubara, T. Uozumi, G. Ghiringhelli, F. Fracassi, C. Dallera, A. Tagliaferri, N.B. Brookes, L. Braicovich, Theoretical and experimental study of resonant inelastic X-ray scattering for NiO, Radiation Physics and Chemistry, 75 (2006) 1670-1675.

[47] J.E. Rubensson, D. Mueller, R. Shuker, D.L. Ederer, C.H. Zhang, J. Jia, T.A. Callcott, Excitationenergy dependence in the $\mathrm{L}_{2,3}$ fluorescence spectrum of Si, Physical Review Letters, 64 (1990) 10471050.

[48] Q.Y. Dong, W.L. O’Brien, J.J. Jia, T.A. Callcott, D.R. Mueller, D.L. Ederer, $\mathrm{Al} \mathrm{L}_{2,3}$ core excitons in $\mathrm{Al}_{\mathrm{x}} \mathrm{Ga}_{1-\mathrm{x}} \mathrm{As}$ studied by soft-x-ray reflection and emission, Physical Review B, 46 (1992) 1511615122.

[49] G. Ghiringhelli, A. Piazzalunga, C. Dallera, G. Trezzi, L. Braicovich, T. Schmitt, V.N. Strocov, R. Betemps, L. Patthey, X. Wang, M. Grioni, SAXES, a high resolution spectrometer for resonant X-ray emission in the 400-1600eV energy range, Review of Scientific Instruments, 77 (2006) 113108.

[50] L.J.P. Ament, M. van Veenendaal, T.P. Devereaux, J.P. Hill, J. van den Brink, Resonant inelastic xray scattering studies of elementary excitations, Reviews of Modern Physics, 83 (2011) 705-767.

[51] T. Tokushima, Y. Horikawa, S. Shin, Triple-path collector optics for grazing incident X-ray emission spectrometer, Review of Scientific Instruments, 82 (2011) 073108.

[52] V.N. Strocov, Concept of a spectrometer for resonant inelastic X-ray scattering with parallel detection in incoming and outgoing photon energies, Journal of synchrotron radiation, 17 (2010) 103-106.

[53] T. Warwick, Y.D. Chuang, D.L. Voronov, H.A. Padmore, A multiplexed high-resolution imaging spectrometer for resonant inelastic soft X-ray scattering spectroscopy, Journal of synchrotron radiation, 21 (2014) 736-743.

[54] J.-H. Guo, T. Tong, L. Svec, J. Go, C. Dong, J.-W. Chiou, Soft-x-ray spectroscopy experiment of liquids, Journal of Vacuum Science \& amp; Technology A, 25 (2007) 1231-1233.

[55] P. Jiang, J.-L. Chen, F. Borondics, P.-A. Glans, M.W. West, C.-L. Chang, M. Salmeron, J. Guo, In situ soft X-ray absorption spectroscopy investigation of electrochemical corrosion of copper in aqueous $\mathrm{NaHCO}_{3}$ solution, Electrochemistry Communications, 12 (2010) 820-822.

[56] J.-H. Guo, The development of in situ photon-in/photon-out soft X-ray spectroscopy on beamline 7.0.1 at the ALS, Journal of Electron Spectroscopy and Related Phenomena, 188 (2013) 71-78.

[57] A.Y. Khodakov, W. Chu, P. Fongarland, Advances in the Development of Novel Cobalt Fischer-Tropsch Catalysts for Synthesis of Long-Chain Hydrocarbons and Clean Fuels, Chemical Reviews, 107 (2007) 1692-1744.

[58] D.K. Bora, P.-A. Glans, J. Pepper, Y.-S. Liu, C. Du, D. Wang, J.-H. Guo, An ultra-high vacuum electrochemical flow cell for in situ/operando soft X-ray spectroscopy study, Review of Scientific Instruments, 85 (2014) 043106. 
[59] S. Myneni, Y. Luo, L.Å. Näslund, M. Cavalleri, L. Ojamäe, H. Ogasawara, A. Pelmenschikov, P. Wernet, P. Väterlein, C. Heske, Z. Hussain, L.G.M. Pettersson, A. Nilsson, Spectroscopic probing of local hydrogen-bonding structures in liquid water, Journal of Physics: Condensed Matter, 14 (2002) L213-L219.

[60] C. Heske, U. Groh, O. Fuchs, L. Weinhardt, E. Umbach, T. Schedel-Niedrig, C.-H. Fischer, M.C. Lux-Steiner, S. Zweigart, T.P. Niesen, F. Karg, J.D. Denlinger, B. Rude, C. Andrus, F. Powell, Monitoring chemical reactions at a liquid-solid interface: Water on $\mathrm{CuIn}(\mathrm{S}, \mathrm{Se})_{2}$ thin film solar cell absorbers, The Journal of Chemical Physics, 119 (2003) 10467-10470.

[61] J.B. MacNaughton, M.V. Yablonskikh, A.H. Hunt, E.Z. Kurmaev, J.S. Lee, S.D. Wettig, A. Moewes, Solid versus solution: Examining the electronic structure of metallic DNA with soft x-ray spectroscopy, Physical Review B, 74 (2006) 125101.

[62] J.-H. Guo, Y. Luo, A. Augustsson, J.E. Rubensson, C. Såthe, H. Ågren, H. Siegbahn, J. Nordgren, XRay Emission Spectroscopy of Hydrogen Bonding and Electronic Structure of Liquid Water, Physical Review Letters, 89 (2002) 137402.

[63] J.-H. Guo, Y. Luo, A. Augustsson, S. Kashtanov, J.E. Rubensson, D.K. Shuh, H. Ågren, J. Nordgren, Molecular Structure of Alcohol-Water Mixtures, Physical Review Letters, 91 (2003) 157401.

[64] O. Fuchs, M. Zharnikov, L. Weinhardt, M. Blum, M. Weigand, Y. Zubavichus, M. Bär, F. Maier, J.D. Denlinger, C. Heske, M. Grunze, E. Umbach, Isotope and Temperature Effects in Liquid Water Probed by X-Ray Absorption and Resonant X-Ray Emission Spectroscopy, Physical Review Letters, 100 (2008) 027801.

[65] Y. Harada, T. Tokushima, Y. Horikawa, O. Takahashi, H. Niwa, M. Kobayashi, M. Oshima, Y. Senba, H. Ohashi, K.T. Wikfeldt, A. Nilsson, L.G.M. Pettersson, S. Shin, Selective Probing of the $\mathrm{OH}$ or OD Stretch Vibration in Liquid Water Using Resonant Inelastic Soft-X-Ray Scattering, Physical Review Letters, 111 (2013) 193001.

[66] J. Barbier Jr, D. Duprez, Steam effects in three-way catalysis, Applied Catalysis B, Environmental, 4 (1994) 105-140.

[67] E.C. Su, W.G. Rothschild, Dynamic behavior of three-way catalysts, Journal of Catalysis, 99 (1986) 506-510.

[68] S.H. Oh, C.C. Eickel, Effects of cerium addition on CO oxidation kinetics over alumina-supported rhodium catalysts, Journal of Catalysis, 112 (1988) 543-555.

[69] T. Bunluesin, E.S. Putna, R.J. Gorte, A comparison of CO oxidation on ceria-supported Pt, Pd, and Rh, Catalysis Letters, 41 (1996) 1-5.

[70] T. Herranz, X. Deng, A. Cabot, J.-H. Guo, M. Salmeron, Influence of the Cobalt Particle Size in the CO Hydrogenation Reaction Studied by In Situ X-Ray Absorption Spectroscopy, The Journal of Physical Chemistry B, 113 (2009) 10721-10727.

[71] S. Alayoglu, S.K. Beaumont, F. Zheng, V.V. Pushkarev, H. Zheng, V. Iablokov, Z. Liu, J.-H. Guo, N. Kruse, G.A. Somorjai, $\mathrm{CO}_{2}$ Hydrogenation Studies on Co and CoPt Bimetallic Nanoparticles Under Reaction Conditions Using TEM, XPS and NEXAFS, Topics in Catalysis, 54 (2011) 778-785.

[72] V. Iablokov, S.K. Beaumont, S. Alayoglu, V.V. Pushkarev, C. Specht, J.-H. Guo, A.P. Alivisatos, N. Kruse, G.A. Somorjai, Size-Controlled Model Co Nanoparticle Catalysts for $\mathrm{CO}_{2}$ Hydrogenation: Synthesis, Characterization, and Catalytic Reactions, Nano Letters, 12 (2012) 3091-3096.

[73] A. Tuxen, S. Carenco, M. Chintapalli, C.-H. Chuang, C. Escudero, E. Pach, P. Jiang, F. Borondics, B. Beberwyck, A.P. Alivisatos, G. Thornton, W.-F. Pong, J.-H. Guo, R. Perez, F. Besenbacher, M. Salmeron, Size-Dependent Dissociation of Carbon Monoxide on Cobalt Nanoparticles, Journal of the American Chemical Society, 135 (2013) 2273-2278.

[74] S. Carenco, A. Tuxen, M. Chintapalli, E. Pach, C. Escudero, T.D. Ewers, P. Jiang, F. Borondics, G. Thornton, A.P. Alivisatos, H. Bluhm, J.-H. Guo, M. Salmeron, Dealloying of Cobalt from CuCo Nanoparticles under Syngas Exposure, The Journal of Physical Chemistry C, 117 (2013) 6259-6266.

[75] C.-S. Li, G. Melaet, W.T. Ralston, K. An, C. Brooks, Y. Ye, Y.-S. Liu, J. Zhu, J.-H. Guo, S. Alayoglu, G.A. Somorjai, High-performance hybrid oxide catalyst of manganese and cobalt for lowpressure methanol synthesis, Nat Commun, 6 (2015). 
[76] M. Bagge-Hansen, B.C. Wood, T. Ogitsu, T.M. Willey, I.C. Tran, A. Wittstock, M.M. Biener, M.D. Merrill, M.A. Worsley, M. Otani, C.-H. Chuang, D. Prendergast, J.-H. Guo, T.F. Baumann, T. van Buuren, J. Biener, J.R.I. Lee, Potential-Induced Electronic Structure Changes in Supercapacitor Electrodes Observed by In Operando Soft X-Ray Spectroscopy, Advanced Materials, 27 (2015) $1512-1518$.

[77] G.A. Somorjai, Y.G. Borodko, Research in Nanosciences - Great Opportunity for Catalysis Science, Catalysis Letters, 76 (2001) 1-5.

[78] Z. Kónya, V. Puntes, I. Kiricsi, J. Zhu, P. Alivisatos, G. Somorjai, Novel Two-Step Synthesis of Controlled Size and Shape Platinum Nanoparticles Encapsulated in Mesoporous Silica, Catalysis Letters, 81 (2002) 137-140.

[79] M. Nagasaka, T. Hatsui, T. Horigome, Y. Hamamura, N. Kosugi, Development of a liquid flow cell to measure soft X-ray absorption in transmission mode: A test for liquid water, Journal of Electron Spectroscopy and Related Phenomena, 177 (2010) 130-134.

[80] M. Freiwald, S. Cramm, W. Eberhardt, S. Eisebitt, Soft X-ray absorption spectroscopy in liquid environments, Journal of Electron Spectroscopy and Related Phenomena, 137-140 (2004) 413-416.

[81] O. Fuchs, F. Maier, L. Weinhardt, M. Weigand, M. Blum, M. Zharnikov, J. Denlinger, M. Grunze, C. Heske, E. Umbach, A liquid flow cell to study the electronic structure of liquids with soft X-rays, Nuclear Instruments and Methods in Physics Research Section A: Accelerators, Spectrometers, Detectors and Associated Equipment, 585 (2008) 172-177.

[82] M. Blum, L. Weinhardt, O. Fuchs, M. Bär, Y. Zhang, M. Weigand, S. Krause, S. Pookpanratana, T. Hofmann, W. Yang, J.D. Denlinger, E. Umbach, C. Heske, Solid and liquid spectroscopic analysis (SALSA)-a soft x-ray spectroscopy endstation with a novel flow-through liquid cell, Review of Scientific Instruments, 80 (2009) 123102.

[83] M. Nagasaka, H. Yuzawa, T. Horigome, N. Kosugi, In operando observation system for electrochemical reaction by soft X-ray absorption spectroscopy with potential modulation method, Review of Scientific Instruments, 85 (2014) 104105.

[84] K.R. Wilson, M. Cavalleri, B.S. Rude, R.D. Schaller, A. Nilsson, L.G.M. Pettersson, N. Goldman, T. Catalano, J.D. Bozek, R.J. Saykally, Characterization of hydrogen bond acceptor molecules at the water surface using near-edge x-ray absorption fine-structure spectroscopy and density functional theory, Journal of Physics: Condensed Matter, 14 (2002) L221-L226.

[85] E.F. Aziz, S. Eisebitt, F. de Groot, J.W. Chiou, C. Dong, J.-H. Guo, W. Eberhardt, Direct Contact versus Solvent-Shared Ion Pairs in NiCl2 Electrolytes Monitored by Multiplet Effects at $\mathrm{Ni}$ (II) $\mathrm{L}$ Edge X-ray Absorption, The Journal of Physical Chemistry B, 111 (2007) 4440-4445.

[86] N. Engel, K. Atak, K.M. Lange, M. Gotz, M. Soldatov, R. Golnak, E. Suljoti, J.-E. Rubensson, E.F. Aziz, DMSO-Water Clustering in Solution Observed in Soft X-ray Spectra, The Journal of Physical Chemistry Letters, 3 (2012) 3697-3701.

[87] B. Dierker, E. Suljoti, K. Atak, K.M. Lange, N. Engel, R. Golnak, M. Dantz, K. Hodeck, M. Khan, N. Kosugi, E.F. Aziz, Probing orbital symmetry in solution: polarization-dependent resonant inelastic soft x-ray scattering on liquid micro-jet, New Journal of Physics, 15 (2013) 093025.

[88] K.M. Lange, E.F. Aziz, Electronic structure of ions and molecules in solution: a view from modern soft X-ray spectroscopies, Chemical Society Reviews, 42 (2013) 6840-6859.

[89] D. Asakura, E. Hosono, H. Niwa, H. Kiuchi, J. Miyawaki, Y. Nanba, M. Okubo, H. Matsuda, H. Zhou, M. Oshima, Y. Harada, Operando soft X-ray emission spectroscopy of $\mathrm{LiMn}_{2} \mathrm{O}_{4}$ thin film involving Li-ion extraction/insertion reaction, Electrochemistry Communications, 50 (2015) 93-96.

[90] M. Gratzel, Photoelectrochemical cells, Nature, 414 (2001) 338-344.

[91] W. Kim, G. Yuan, B.A. McClure, H. Frei, Light Induced Carbon Dioxide Reduction by Water at Binuclear $\mathrm{ZrOCo}^{\mathrm{II}}$ Unit Coupled to Ir Oxide Nanocluster Catalyst, Journal of the American Chemical Society, 136 (2014) 11034-11042.

[92] V.F. Puntes, K.M. Krishnan, A.P. Alivisatos, Colloidal Nanocrystal Shape and Size Control: The Case of Cobalt, Science, 291 (2001) 2115-2117. 
[93] V.F. Puntes, P. Gorostiza, D.M. Aruguete, N.G. Bastus, A.P. Alivisatos, Collective behaviour in two-dimensional cobalt nanoparticle assemblies observed by magnetic force microscopy, Nat Mater, 3 (2004) 263-268.

[94] H. Liu, J.-H. Guo, Y. Yin, A. Augustsson, C. Dong, J. Nordgren, C. Chang, P. Alivisatos, G. Thornton, D.F. Ogletree, F.G. Requejo, F. de Groot, M. Salmeron, Electronic Structure of Cobalt Nanocrystals Suspended in Liquid, Nano Letters, 7 (2007) 1919-1922.

[95] B. Freelon, A. Augustsson, J.-H. Guo, P.G. Medaglia, A. Tebano, G. Balestrino, Electron Correlation and Charge Transfer in $\left[\left(\mathrm{Ba}_{0.9} \mathrm{Nd}_{0.1}\right) \mathrm{CuO}_{2+\delta}\right]_{2} /\left[\mathrm{CaCuO}_{2}\right]_{2}$ Superconducting Superlattices, Physical Review Letters, 96 (2006) 017003.

[96] F. Jiao, H. Frei, Nanostructured Cobalt Oxide Clusters in Mesoporous Silica as Efficient OxygenEvolving Catalysts, Angewandte Chemie, 121 (2009) 1873-1876.

[97] S.G. Y.-S. Liu, J.-L. Liu, F. Jiao, P.-A. Glans, J. Zhang, H. Frei, and J.-H. Guo, Electronic Structure Study of Nanostructured Cobalt Oxide Clusters in Mesoporous Silica as Efficient Oxygen-Evolving Catalysts, to be submitted, (2015).

[98] Y. Lin, Z. Jiang, C. Zhu, X. Hu, X. Zhang, H. Zhu, J. Fan, S.H. Lin, Electronic and optical performances of $\mathrm{Si}$ and $\mathrm{Fe}$-codoped $\mathrm{TiO} 2$ nanoparticles: A photocatalyst for the degradation of methylene blue, Applied Catalysis B: Environmental, 142-143 (2013) 38-44.

[99] Y. Cao, T. He, Y. Chen, Y. Cao, Fabrication of Rutile $\mathrm{TiO}_{2}-\mathrm{Sn} /$ Anatase $\mathrm{TiO}_{2}-\mathrm{N}$ Heterostructure and Its Application in Visible-Light Photocatalysis, The Journal of Physical Chemistry C, 114 (2010) 3627-3633.

[100] G.K. Larsen, B.C. Fitzmorris, C. Longo, J.Z. Zhang, Y. Zhao, Nanostructured homogenous CdSe$\mathrm{TiO}_{2}$ composite visible light photoanodes fabricated by oblique angle codeposition, Journal of Materials Chemistry, 22 (2012) 14205-14218.

[101] J.R.I. Lee, H.D. Whitley, R.W. Meulenberg, A. Wolcott, J.Z. Zhang, D. Prendergast, D.D. Lovingood, G.F. Strouse, T. Ogitsu, E. Schwegler, L.J. Terminello, T. van Buuren, LigandMediated Modification of the Electronic Structure of CdSe Quantum Dots, Nano Letters, 12 (2012) 2763-2767.

[102] B.C. Fitzmorris, G.K. Larsen, D.A. Wheeler, Y. Zhao, J.Z. Zhang, Ultrafast Charge Transfer Dynamics in Polycrystalline $\mathrm{CdSe} / \mathrm{TiO}_{2}$ Nanorods Prepared by Oblique Angle Codeposition, The Journal of Physical Chemistry C, 116 (2012) 5033-5041.

[103] S.Y. Huang, Rocking Chair Lithium Battery Based on Nanocrystalline $\mathrm{TiO}_{2}$ (Anatase), Journal of The Electrochemical Society, 142 (1995) L142.

[104] A. Hagfeldt, Fast Electrochromic Switching with Nanocrystalline Oxide Semiconductor Films, Journal of The Electrochemical Society, 141 (1994) L82.

[105] A. Augustsson, A. Henningsson, S.M. Butorin, H. Siegbahn, J. Nordgren, J.-H. Guo, Lithium ion insertion in nanoporous anatase $\mathrm{TiO}_{2}$ studied with RIXS, The Journal of Chemical Physics, 119 (2003) 3983-3987.

[106] S.M. Butorin, J.H. Guo, M. Magnuson, J. Nordgren, Resonant inelastic soft-x-ray scattering from valence-band excitations in $3 d^{0}$ compounds, Physical Review B, 55 (1997) 4242-4249.

[107] G. Ghiringhelli, A. Piazzalunga, C. Dallera, T. Schmitt, V.N. Strocov, J. Schlappa, L. Patthey, X. Wang, H. Berger, M. Grioni, Observation of Two Nondispersive Magnetic Excitations in NiO by Resonant Inelastic Soft-X-Ray Scattering, Physical Review Letters, 102 (2009) 027401.

[108] C. Ulrich, L.J.P. Ament, G. Ghiringhelli, L. Braicovich, M. Moretti Sala, N. Pezzotta, T. Schmitt, G. Khaliullin, J. van den Brink, H. Roth, T. Lorenz, B. Keimer, Momentum Dependence of Orbital Excitations in Mott-Insulating Titanates, Physical Review Letters, 103 (2009) 107205.

[109] S. Glawion, J. Heidler, M.W. Haverkort, L.C. Duda, T. Schmitt, V.N. Strocov, C. Monney, K.J. Zhou, A. Ruff, M. Sing, R. Claessen, Two-Spinon and Orbital Excitations of the Spin-Peierls System TiOCl, Physical Review Letters, 107 (2011) 107402.

[110] J. Schlappa, K. Wohlfeld, K.J. Zhou, M. Mourigal, M.W. Haverkort, V.N. Strocov, L. Hozoi, C. Monney, S. Nishimoto, S. Singh, A. Revcolevschi, J.S. Caux, L. Patthey, H.M. Ronnow, J. van den 
Brink, T. Schmitt, Spin-orbital separation in the quasi-one-dimensional Mott insulator $\mathrm{Sr}_{2} \mathrm{CuO}_{3}$, Nature, 485 (2012) 82-85.

[111] F. Hennies, A. Pietzsch, M. Berglund, A. Föhlisch, T. Schmitt, V. Strocov, H.O. Karlsson, J. Andersson, J.-E. Rubensson, Resonant Inelastic Scattering Spectra of Free Molecules with Vibrational Resolution, Physical Review Letters, 104 (2010) 193002.

[112] A. Pietzsch, Y.P. Sun, F. Hennies, Z. Rinkevicius, H.O. Karlsson, T. Schmitt, V.N. Strocov, J. Andersson, B. Kennedy, J. Schlappa, A. Föhlisch, J.E. Rubensson, F. Gel'mukhanov, Spatial Quantum Beats in Vibrational Resonant Inelastic Soft X-Ray Scattering at Dissociating States in Oxygen, Physical Review Letters, 106 (2011) 153004.

[113] C. H. Chuang, M. Kapilashrami, S. Gul, , G. Wang, C.-M, Chen, Y. C. Shao, P.-H. Yeh, C.-M. Chang, Y. Li, J. Zhang, H. Niwa, J. Miyawkai, Y. Harada, J.-M. Chen, W.-F. Pong, J.-H. Guo, Molecular Adsorption and Interfacial Vibrational Coupling on $\mathrm{TiO}_{2}$ Nanowires Revealed by Resonant Inelastic X-ray Scattering, to be submitted (2015). 